\title{
The changes of non-invasive hemoglobin and perfusion index of Pulse CO-Oximetry during induction of general anesthesia
}

\author{
Seul Gi Park, Oh Haeng Lee, Yong-Hee Park, Hwa Yong Shin, Hyun Kang, \\ Chong Wha Baek, Yong Hun Jung, and Young Cheol Woo \\ Department of Anesthesiology and Pain Medicine, Chung-Ang University College of Medicine, Seoul, Korea
}

\begin{abstract}
Background: We hypothesized that induction of general anesthesia using sevoflurane improves the accuracy of noninvasive hemoglobin (SpHb) measurement of Masimo Radical $-7^{\circledR}$ Pulse CO-Oximetry by inducing peripheral vasodilation and increasing the perfusion index (PI). The aim of this study is to investigate the change in the SpHb and the PI measured by Rad7 during induction of general anesthesia using sevoflurane.

Methods: The laboratory hemoglobin $\left(\mathrm{Hb}_{\mathrm{lab}}\right)$ was measured before surgery by venous blood sampling. The $\mathrm{SpHb}$ and the PI was measured twice; before and after the induction of general anesthesia using sevoflurane. The changes of SpHb, $\mathrm{Hb}_{\text {bias }}\left(\mathrm{Hb}_{\text {bias }}=\mathrm{SpHb}-\mathrm{Hb}_{\text {lab }}\right)$, and PI before and after the induction of general anesthesia were analyzed using a paired $\mathrm{t}-$ test. Also, a Pearson correlation coefficient analysis was used to analyze the correlation between the $\mathrm{Hb}_{\text {bias }}$ and the PI.

Results: The SpHb and the PI were increased after the induction of general anesthesia using sevoflurane. There was a statistically significant change in the $\mathrm{Hb}_{\text {bias }}$ from -2.8 to -0.7 after the induction of general anesthesia. However, the limit of agreement (2 SD) of the $\mathrm{Hb}_{\text {bias }}$ did not change after the induction of general anesthesia. The Pearson correlation coefficient between the $\mathrm{Hb}_{\text {bias }}$ and the PI was not statistically significant.

Conclusions: During induction of general anesthesia using sevoflurane, the accuracy of SpHb measurement was improved and precision was not changed. The correlation between $\mathrm{Hb}_{\text {bias }}$ and PI was not significant.
\end{abstract}

Key Words: Hemoglobin, Masimo, Perfusion index, Pulse CO-Oximetry, Sevoflurane.

Corresponding author: Young Cheol Woo, M.D., Ph.D.

Department of Anesthesiology and Pain Medicine, Chung-Ang University College of Medicine, 102, Heukseok-ro, Dongjak-gu, Seoul 156-755, Korea

Tel: 82-2-6299-2579, Fax: 82-2-6299-2585

E-mail: wj12@naver.com

This is a thesis for a Master's degree by Seul Gi Park.

Received: September 3, 2014.

Revised: January 7, 2015.

Accepted: January 27, 2015.

Korean J Anesthesiol 2015 August 68(4): 352-357

http://dx.doi.org/10.4097/kjae.2015.68.4.352

\section{Introduction}

Pulse CO-Oximetry was recently developed and has since been used to non-invasively measure hemoglobin in the blood. Masimo Radical- $7^{\circledR}$ Pulse CO-Oximetry (Rad7; Masimo Corp., Irvine, CA, USA) uses spectrophotometry and detects the total hemoglobin $(\mathrm{SpHb})$ immediately, continuously, and noninvasively by placing a disposable or reusable sensor on a fingertip or an earlobe.

The standard method of measuring hemoglobin $\left(\mathrm{Hb}_{\mathrm{lab}}\right)$ using an automated hematology analyzer [1] takes long time to produce results and requires blood sampling, which makes it an invasive procedure. Rad7 can measure the $\mathrm{SpHb}$ and also measures carboxyhemoglobin, methemoglobin, and the pleth vari-

(c) This is an open-access article distributed under the terms of the Creative Commons Attribution Non-Commercial License (http://creativecommons.org/ licenses/by-nc/4.0/), which permits unrestricted non-commercial use, distribution, and reproduction in any medium, provided the original work is properly cited. 
ability index, oxygen content, arterial oxygen saturation, pulse rate, and perfusion index (PI) [2].

Most of the previous studies on the accuracy of $\mathrm{SpHb}$ were conducted among healthy patients who had not undergone surgery or among acutely or severely ill patients [3-5]. Some other studies have been conducted on patients who had undergone surgery under general anesthesia, but those were often limited to certain types of surgery and the methods of their general anesthesia were often not elaborated enough or not mentioned at all [6-8]. The PI is the calculated value using the pulse strength of the monitoring site. However, the influence of PI on the accuracy of noninvasive hemoglobin monitoring is not defined. In our knowledge, there has been little study on the effect of inhalation anesthesia on the measurement of $\mathrm{SpHb}$ or on the correlation between inhalation anesthesia and PI. Sevoflurane, an inhalation anesthetic, induces dilatation of peripheral blood vessels, particularly arteriole, which increases the blood flow $[9,10]$. The dilatation of peripheral blood vessels by sevoflurane is believed to increase the PI and improve the accuracy of SpHb measurement, but this assumption has no solid evidence due to lack of studies. Therefore, we aimed to investigate the change in the $\mathrm{SpHb}$ and the PI measured by Rad7 when general anesthesia using sevoflurane was applied.

\section{Materials and Methods}

This study was conducted from April 2014 to May 2014 after its approval by the Institutional Review Board of our hospital where this study was performed. The objectives and methods of this study were explained to all the patients, and they were asked to signify their informed consent by signing the informed consent form. The study protocol was registered at Clinical Research Information Service. American Society of Anesthesiologists physical status I and II adult patients who underwent surgery under general anesthesia were enrolled in this study. Patients aged 65 years or more, or those who were diagnosed with peripheral vascular disease or arrhythmia, or showed a poor Rad7 signal, or whose blood pressure and $\mathrm{SpHb}$ had to be measured on the same side arm and finger were excluded from this study.

The laboratory $\mathrm{Hb}$ was measured by using the automated hematology analyzer XE-2100 ${ }^{\circledR}$ (Sysmex Corp., Kobe, Japan) from the patient's venous blood before the surgery. The Blood sample was done around 1-5 days before the surgery and if the $\mathrm{Hb}$ value was abnormal ( $\leq 13$ or $\geq 17 \mathrm{~g} / \mathrm{dl}$ ), the CBC (complete blood count) was rechecked before the day of surgery. The latest $\mathrm{Hb}$ value was used and compared with the SpHb. We presumed that the patients who were enrolled in this study did not undergo a clinically significant physiologic or pathologic change until the entering the day of surgery. XE- $2100^{\circledR}$ is very accurate, with a determination coefficient or $\mathrm{R}^{2}=0.9916$, when compared with an experienced laboratory medicine specialist counting the RBCs with his naked eyes, and it has a high variation coefficient for precision, repeatability, and reproducibility [11]. Our hospital performs a quality control procedure for specimen tests daily following the recommendation of the manufacturer.

Enrolled patients were fasting from midnight before the surgery and the intravenous fluid was infused for maintenance dose till the surgery.

After the patients entered the operating room, their electrocardiogram and blood pressure were measured non-invasively using a monitoring device (Datex-Ohmeda, GE Healthcare, Little Chalfont, UK). A reusable Rad7 sensor was attached to their index or middle fingertip, and the sensor was covered with a black, opaque protector to reduce the interference by the surrounding lights, as recommended by the manufacturer. Then the sensor was connected to the Rad7 to measure the SpHb and the PI. The Rad7 used in this study was equipped with a software ver. 7.8.0.1 (Masimo Corp., Irvine, CA, USA), and the R2-25 Revision E sensor (Masimo Corp., Irvine, CA, USA) was used.

For the induction of general anesthesia, $40 \mathrm{mg}$ of $2 \%$ lidocaine and 1-2 $\mathrm{mg} / \mathrm{kg}$ propofol were administered intravenously, and $0.6-0.9 \mathrm{mg} / \mathrm{kg}$ rocuronium was administered after unconsciousness was confirmed. Then manual ventilation was performed using 3-5 vol\% sevoflurane and $100 \%$ oxygen to maintain 35-40 mmHg of end tidal carbon dioxide. The volume of intravenous fluid administration used to induce general anesthesia was $50 \mathrm{ml}$ or less.

After the baseline vital sign was checked and the SpHb and the PI of Rad7 got stabilized for 120s, the SpHb and the PI was recorded (pre-SpHb and pre-PI). After the induction of general anesthesia using sevoflurane while performing manual ventilation, the measurement was repeated (post-SpHb and post-PI). The recording of the SpHb and PI was performed by the anesthesiologists who do not know the patient's $\mathrm{Hb}_{\mathrm{lab}}$. From the initiation of the manual ventilation, the time for measurement of the $\mathrm{SpHb}$ and the PI took less than 5 minutes, and were followed by endotracheal intubation. $\mathrm{Hb}_{\text {bias }}$ is difference between the $\mathrm{SpHb}$ and the $\mathrm{Hb}_{\text {lab }}\left(\mathrm{Hb}_{\text {bias }}=\mathrm{SpHb}-\mathrm{Hb}_{\text {lab }}\right)$, and this calculated value was obtained before and after the induction of general anesthesia using sevoflurane.

The primary objective of this study was to investigate the effect of general anesthesia using sevoflurane on the accuracy of $\mathrm{SpHb}$ measurement using Rad7 by measuring the $\mathrm{Hb}_{\text {bias }}$. The second objective of this study was to analyze the correlation of $\mathrm{Hb}_{\text {bias }}$ and the PI.

The changes of the $\mathrm{SpHb}, \mathrm{Hb}_{\text {bias }}$, and PI before and after the induction of general anesthesia were analyzed using a paired t-test. From the change of $\mathrm{Hb}_{\text {bias }}$, the changes of accuracy and precision were evaluated. For statistical description, the meaning of 'accuracy' is used to describe as how close a measured 
value is to the actual value and the meaning of 'precision' is used to describe as how close a measured value are to each other. To compare the two types of hemoglobin results represented by the $\mathrm{SpHb}$ and the $\mathrm{Hb}_{\mathrm{lab}}$, a Bland and Altman plot was performed. Also, a Pearson correlation coefficient analysis was used to analyze the correlation between the $\mathrm{SpHb}$ and the $\mathrm{Hb}_{\mathrm{lab}}$ and between the $\mathrm{Hb}_{\text {bias }}$ and the PI. To investigate the power of the $\mathrm{SpHb}$ to explain the $\mathrm{Hb}_{\mathrm{lab}}$ result, a regression analysis was performed. All the variables were represented as mean \pm standard deviations, and the $\mathrm{P}$ value $<0.05$ were considered statistically significant. IBM SPSS ${ }^{\circledR} 21$ (IBM Co., Armonk, NY, USA) was used for the statistical analysis, and the figures were drawn us-

Table 1. Demographic Data

$\begin{array}{lc}\text { Age }(\mathrm{yr}) & 37.5 \pm 12.5 \\ \text { Gender }(\mathrm{M} / \mathrm{F}) & 11 / 15 \\ \text { Height }(\mathrm{cm}) & 165.2 \pm 8.7 \\ \text { Weight }(\mathrm{kg}) & 65.3 \pm 10.1 \\ \mathrm{Hb} \text { lab }(\mathrm{g} / \mathrm{dl}) & 14.2 \pm 1.6 \\ \text { Body mass index }\left(\mathrm{kg} / \mathrm{m}^{2}\right) & 23.9 \pm 2.8 \\ \text { ASA } 1 / 2 & 19 / 7 \\ \text { Type of surgery }(\mathrm{n}) & \\ \quad \text { General surgery } & 8 \\ \text { Maxillofacial surgery } & 6 \\ \text { Orthopedic surgery } & 6 \\ \text { Gynecology } & 2 \\ \text { Otolaryngology } & 2 \\ \text { Eye surgery } & 1 \\ \text { Urology } & 1\end{array}$

Values are mean \pm SD or number (\%). $\mathrm{Hb}_{\mathrm{lab}}$ : automated laboratory hemoglobin. ASA: American Society of Anesthesiologists physical status classification.

A

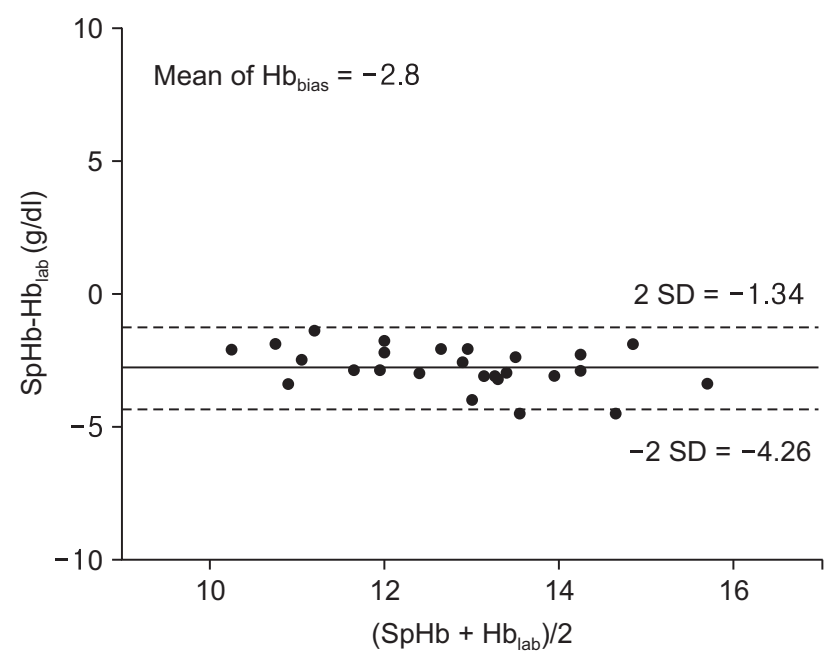

ing the SigmaPlot ${ }^{\circledR} 10.0 \mathrm{~K}$ (Systat Software, Inc., San Jose, CA, USA) program. The preliminary study conducted on 10 patients showed that the standard deviation of $\mathrm{Hb}_{\text {bias }}$ difference between before and after the induction of general anesthesia was $0.7 \mathrm{~g} / \mathrm{dl}$. Based on this result, we assumed that the general anesthesia using sevoflurane would induce the change of $0.5 \mathrm{~g} / \mathrm{dl}$ of $\mathrm{Hb}_{\text {bias }}$ difference, and we calculated the sample size using a 0.05 significance level and 0.9 statistical power. Twenty-three patients were required based on the calculation, but considering the $10 \%$ drop-out rate, a total of 26 patients were required.

\section{Results}

A total of 26 patients were enrolled, and none of them was withdrawn from the study. The demographic data of the patients are presented in Table 1. The changes of hemodynamic and measurements in pulse CO-Oximetry before and after induction of

Table 2. The Changes of SpHb, PI, MBP and HR

\begin{tabular}{lcc}
\hline & $\begin{array}{c}\text { Before induction } \\
(\mathrm{N}=26)\end{array}$ & $\begin{array}{c}\text { After induction } \\
(\mathrm{N}=26)\end{array}$ \\
\hline $\mathrm{SpHb}(\mathrm{g} / \mathrm{dl})$ & $11.4 \pm 1.3$ & $13.5 \pm 1.5^{*}$ \\
$\mathrm{Hb}_{\text {bias }}(\mathrm{g} / \mathrm{dl})$ & $-2.8 \pm 0.8$ & $-0.7 \pm 0.7^{*}$ \\
$\left|\mathrm{Hb}_{\text {bias }}\right|<1 \mathrm{~g} / \mathrm{dl}(\mathrm{n},[\%])$ & $0(0)$ & $22(84.6)^{*}$ \\
$\mathrm{PI}(\%)$ & $1.1 \pm 0.4$ & $5.8 \pm 1.7^{*}$ \\
$\mathrm{MBP}(\mathrm{mmHg})$ & $102.1 \pm 16.1$ & $84.7 \pm 10.9^{*}$ \\
$\mathrm{HR}($ beats/min $)$ & $74.9 \pm 13.7$ & $73.9 \pm 12.7$ \\
\hline
\end{tabular}

Values are mean \pm SD or number (\%). SpHb: continuous non-invasive hemoglobin, $\mathrm{Hb}_{\text {bias }}$ : $\mathrm{SpHb}-\mathrm{Hb}_{\text {lab }}$, PI: perfusion index, MBP: mean blood pressure, HR: heart rate. ${ }^{*} \mathrm{P}<0.001$.

B

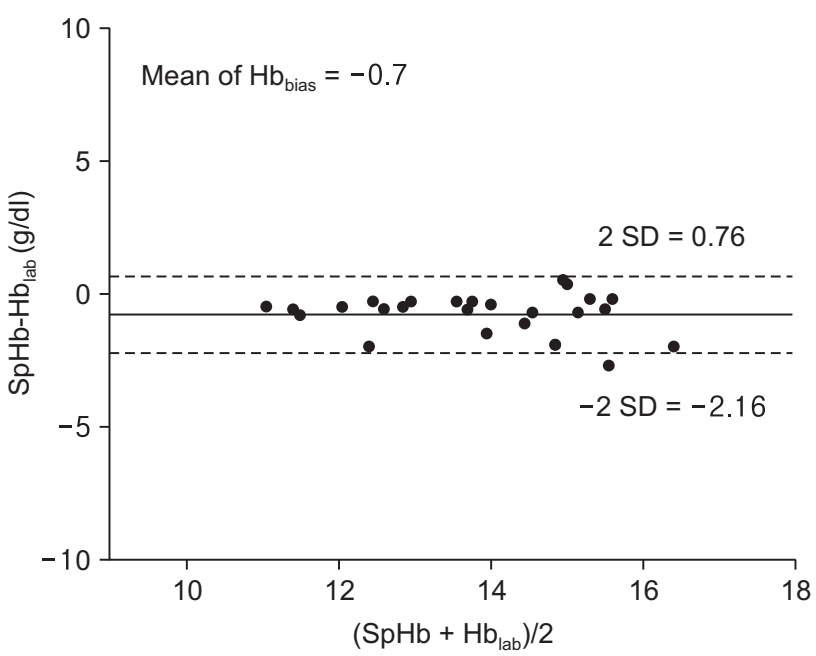

Fig. 1. Bland and Altman plot of $\mathrm{SpHb}$ and $\mathrm{Hb}_{\mathrm{lab}}$ (A) before induction of general anesthesia using sevoflurane and (B) after induction of general anesthesia using sevoflurane. The horizontal plain lines correspond to the mean of $\mathrm{Hb}_{\text {bias }}$ and dotted lines correspond to the limits of agreement (2 SD). Each point represents the $\mathrm{Hb}_{\text {bias }}$ of a single patient. 
general anesthesia are listed in Table 2 . The mean value of pre$\mathrm{SpHb}$ was $11.4 \pm 1.3 \mathrm{~g} / \mathrm{dl}$ and post-SpHb was $13.5 \pm 1.5 \mathrm{~g} / \mathrm{dl}$ $(\mathrm{P}<0.001)$. The PI also increased significantly after the induction of general anesthesia using sevoflurane $(\mathrm{P}<0.001)$. Before induction of general anesthesia, PI $<1.0$ was obtained in $46.2 \%$ $(12 / 26)$ of patients and there was only 1 patient whose PI was over 2.0. However, there was no patient with PI below 1.0 after general anesthesia was performed and the lowest PI value was 3.2. The Bland and Altman plot showed a statistically significant change in the mean of $\mathrm{Hb}_{\text {bias }}$ from $-2.8 \pm 0.8 \mathrm{~g} / \mathrm{dl}$ before the induction of general anesthesia to $-0.7 \pm 0.7 \mathrm{~g} / \mathrm{dl}$ after the induction of general anesthesia using sevoflurane $(\mathrm{P}<0.001)$. However, the limits of agreement (2 SD) of the $\mathrm{Hb}_{\text {bias }}$ before the induction of general anesthesia did not change and remained at same level after induction of general anesthesia using sevoflurane (Fig. 1). The Pearson correlation coefficient analysis showed that the $\mathrm{SpHb}$ and the $\mathrm{Hb}_{\mathrm{lab}}$ were significantly correlated both before and after the induction of general anesthesia $(\mathrm{P}<0.001)$ (Table 3). The power of the $\mathrm{SpHb}$ to explain the $\mathrm{Hb}_{\mathrm{lab}}$ result was

Table 3. Pearson Correlation Coefficient between $\mathrm{SpHb}, \mathrm{Hb}_{\mathrm{lab}}, \mathrm{Hb}_{\text {bias}}$, and PI

\begin{tabular}{lcc}
\hline & $\mathrm{r}$ & P value \\
\hline Pre-SpHb vs Hb $_{\text {lab }}$ & 0.868 & $<0.001$ \\
Post-SpHb vs Hb $_{\text {lab }}$ & 0.884 & $<0.001$ \\
Pre-Hb $_{\text {bias }}$ vs pre-PI & 0.013 & 0.951 \\
Post-Hb $_{\text {bias }}$ vs post-PI & 0.206 & 0.313
\end{tabular}

r: correlation coefficient. Pre: before induction of general anesthesia using sevoflurane, $\mathrm{SpHb}$ : continuous non-invasive hemoglobin, $\mathrm{Hb}_{\mathrm{lab}}$ : automated laboratory hemoglobin, Post: after induction of general anesthesia using sevoflurane, $\mathrm{Hb}_{\text {bias }}$ : $\mathrm{SpHb}-\mathrm{Hb}_{\mathrm{lab}}$, $\mathrm{PI}$ : perfusion index.

A

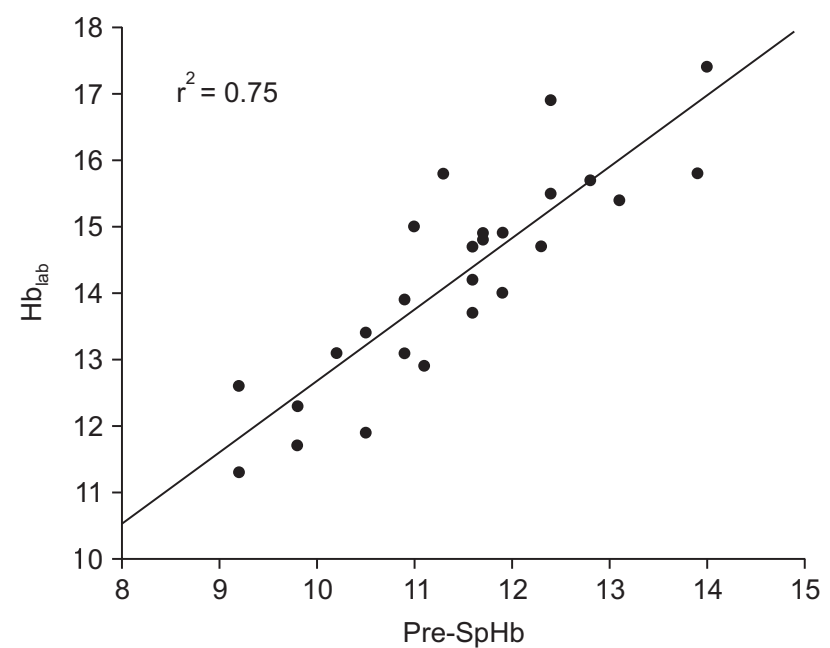

$r^{2}=0.75$ before the induction of general anesthesia, and was $r^{2}=$ 0.78 after the induction of general anesthesia using sevoflurane (Fig. 2).

\section{Discussion}

We aimed to investigate the accuracy of SpHb using Rad7 by measuring the change in the $\mathrm{Hb}_{\text {bias }}$ and the PI as possible cause of the change during induction of general anesthesia using sevoflurane. The results showed that the $\mathrm{Hb}_{\text {bias }}$ decreased and the PI increased after the induction of general anesthesia using sevoflurane.

The principles of hemoglobin measurement using Rad7 are similar to those of oxygen saturation measurement using a conventional pulse oximeter. The difference between the Rad7 device and a pulse oximeter is that $\operatorname{Rad} 7$ uses more than seven wavelengths that pass through the fingertip, whereas a pulse oximeter uses only two wavelengths. Various lights with different wavelengths are made to pass through the fingertip or earlobe, and are captured with a photodiode receptor. This light energy is changed to electronic energy, then to digital signal, and the figures are represented as numeric values on the screen of the Rad7 device [12].

In one of previous studies, the $\mathrm{SpHb}$ after hemodilution in healthy adults showed $0.15 \mathrm{~g} / \mathrm{dL}$ of $\mathrm{Hb}_{\text {bias }}$ with precision $0.92 \mathrm{~g} /$ $\mathrm{dl}$, and clinically high accuracy against $\mathrm{Hb}_{\mathrm{lab}}$ [13]. Moreover, the $\mathrm{SpHb}$ measured in the acutely or severely ill patients in the intensive care unit (ICU) showed excellent accuracy in the wide range of the $\mathrm{Hb}_{\text {lab }}$ value $\left(\mathrm{Hb}_{\text {bias }}: 0.0 \mathrm{~g} / \mathrm{dl}\right.$, limits of agreement: \pm $1.0 \mathrm{~g} / \mathrm{dl}$ ) [4]. However, the studies on patients admitted to the emergency room and who had undergone surgery for hemor-

B

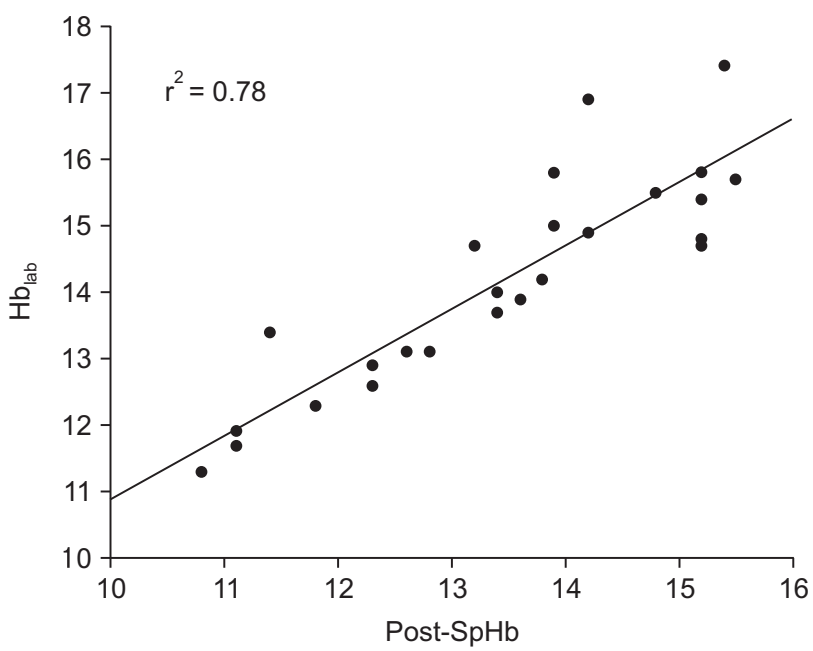

Fig. 2. Regression analysis between $\mathrm{SpHb}$ and $\mathrm{Hb}_{\mathrm{lab}}(\mathrm{A})$ before induction of general anesthesia using sevoflurane and (B) after induction of general anesthesia using sevoflurane. 
rhagic diseases reported a lower $\mathrm{SpHb}$ than $\mathrm{Hb}_{\mathrm{lab}}$ and pointed out that Rad7 was inappropriate for evaluating the adequacy of blood transfusion $[12,14]$. In our study, the absolute value of the $\mathrm{Hb}_{\text {bias }}$ decreased after the induction of general anesthesia (pre$\mathrm{Hb}_{\text {bias: }}:-2.8 \mathrm{~g} / \mathrm{dl}$, post- $\left.\mathrm{Hb}_{\text {bias }}:-0.7 \mathrm{~g} / \mathrm{dl}\right)$, and the limits of agreement of the $\mathrm{Hb}_{\text {bias }}(2 \mathrm{SD})$ remained the same level $( \pm 1.46 \mathrm{~g} / \mathrm{dl})$. When the less than $1 \mathrm{~g} / \mathrm{dl}$ absolute value of the $\mathrm{Hb}_{\text {bias }}$ was assumed to have been clinically acceptable, no patient showed less than $1 \mathrm{~g} / \mathrm{dl}$ of $\mathrm{Hb}_{\text {bias }}$ before the induction of general anesthesia, but 22 out of the 26 patients $(84.6 \%)$ did so after the induction of general anesthesia using sevoflurane. Based on these results, we concluded that the accuracy of Rad7 in measuring the SpHb increased with the same precision after the induction of general anesthesia. As such, the measurement of hemoglobin using Rad7 can be considered as an option after the induction of general anesthesia.

The PI is an indirect indicator of peripheral circulation and is obtained by calculating the ratio of the amplitude of the arterial pulse detected by the Rad7 sensor to the amplitude of nonpulsatile factors such as the veins, bones, or subcutaneous fats [5]. The amplitude of the non-pulsatile factors remains almost the same regardless of the dilatation or contraction of the vessels, so the change in the amplitude of the arterial pulse mostly determines the PI [15]. The PI is an important factor to consider in evaluating the accuracy of SpHb measurement. Nguyen et al. [5] reported that the absolute value of $\mathrm{Hb}_{\text {bias }}$ decreased when the PI was over 2.0 in patients who had undergone cardiac surgery and received intensive care in the ICU. Miller et al. [16] reported highly accurate $\mathrm{Hb}_{\text {bias }}$ measurement in patients with a PI $>2.0$ after the peripheral nerve of their fingers was blocked with local anesthetics. Similarly, the PI was significantly increased after spinal anesthesia and discrepancy between $\mathrm{SpHb}$ and laboratory $\mathrm{Hb}$ was decreased [17]. In our study, 25 (96.1\%) of the 26 patients showed a PI $<2.0$ before the induction of general anesthesia, but the PI increase to above 3.0 in all patients and the $\mathrm{Hb}_{\text {bias }}$ decreased after the induction of general anesthesia using sevoflurane. However, the correlation between the $\mathrm{Hb}_{\text {bias }}$ and the PI was not statistically significant even when the PI increased to more than 3.0 after the induction of general anesthesia using sevoflurane. This result was considered similar to that of a previous report that the accuracy of the $\mathrm{Hb}_{\text {bias }}$ did not increase proportionally to the PI increase [6]. However, we can suggest that the adequate peripheral perfusion is an important factor to make the $\mathrm{SpHb}$ value reliable.

The determination coefficient of the $\mathrm{SpHb}$ before and after the induction of general anesthesia was obtained using regression analysis to analyze the power of the $\mathrm{SpHb}$ to explain the $\mathrm{Hb}_{\text {lab }}$ result. Compared to the previous studies that reported that the determination coefficient of the $\mathrm{SpHb}$ to the $\mathrm{Hb}_{\text {lab }}$ was $\mathrm{r}^{2}=$ 0.41 in acutely or severely ill patients in the ICU, and $\mathrm{r}^{2}=0.30$ in patients with severe gastric hemorrhage $[3,4]$, in this study the determination coefficient of the $\mathrm{SpHb}$ to the $\mathrm{Hb}_{\mathrm{lab}}$ was $\mathrm{r}^{2}=0.75$ before the induction of general anesthesia and $r^{2}=0.78$ after the induction of general anesthesia using sevoflurane, which is higher than those in previous studies. The ranges of the $\mathrm{Hb}_{\mathrm{lab}}$ in previous studies were $6.6-14.9 \mathrm{~g} / \mathrm{dl}$ and $6.8-16.2 \mathrm{~g} / \mathrm{dl}$, respectively, and norepinephrine, a vasoconstrictor, was used in 18 and $34 \%$ of the study patients. On the other hand, the range of the $\mathrm{Hb}_{\mathrm{lab}}$ in this study was $11.3-17.4 \mathrm{~g} / \mathrm{dl}$, and the patients were healthy adult who did not require the use of a vasoconstrictor. As such, we consider that they may cause the higher power of the SpHb to explain the $\mathrm{Hb}_{\mathrm{lab}}$ in this study than those in previous studies.

The limitations of this study included a maximum SpHb measurement duration of only 5 minutes during the induction of general anesthesia using sevoflurane. The dose and duration of the used sevoflurane determines the degree of dilatation of the vessels [18]. In the previous study, even the technique of general anesthesia induction was not described, the longer operating time showed improved accuracy of the $\mathrm{SpHb}$ in the patients who had undergone spinal surgery under general anesthesia [6]. As such, the accuracy of the SpHb and the PI possibly improved in time after the induction of general anesthesia using sevoflurane. Moreover, the effects of various anesthetics administered intravenously to induce general anesthesia on the dilatation or contraction of the vessels could not be ruled out. In particular, propofol causes vasodilation when $1-2 \mathrm{mg} / \mathrm{kg}$ of it is once injected to induce general anesthesia [19]. As such, propofol might have also increased the PI, besides sevoflurane.

In conclusion, the accuracy of $\mathrm{SpHb}$ measurement using Rad7 improved, its precision was maintained, and the PI increased during the induction of general anesthesia using sevoflurane. The correlation of the $\mathrm{Hb}_{\text {bias }}$ and the PI was insignificant before and after the induction of general anesthesia using sevoflurane. The measurement of the SpHb using Rad7 can be a supplementary and helpful method of evaluating the hemoglobin of patients during general anesthesia for their safety.

\section{References}

1. International committee for standardization in haematology. Recommendations for haemoglobinometry in human blood. Br J Haematol 1967; 13: 71-5.

2. Lindner G, Exadaktylos AK. How noninvasive haemoglobin measurement with pulse co-oximetry can change your practice: An expert 
review. Emerg Med Int 2013; 2013: 701529.

3. Coquin J, Dewitte A, Manach YL, Caujolle M, Joannes-Boyau O, Fleureau C, et al. Precision of noninvasive hemoglobin-level measurement by pulse co-oximetry in patients admitted to intensive care units for severe gastrointestinal bleeds. Crit Care Med 2012; 40: 2576-82.

4. Frasca D, Dahyot-Fizelier C, Catherine K, Levrat Q, Debaene B, Mimoz O. Accuracy of a continuous noninvasive hemoglobin monitor in intensive care unit patients. Crit Care Med 2011; 39: 2277-82.

5. Nguyen BV, Vincent JL, Nowak E, Coat M, Paleiron N, Gouny P, et al. The accuracy of noninvasive hemoglobin measurement by multiwavelength pulse oximetry after cardiac surgery. Anesth Analg 2011; 113: 1052-7.

6. Miller RD, Ward TA, Shiboski SC, Cohen NH. A comparison of three methods of hemoglobin monitoring in patients undergoing spine surgery. Anesth Analg 2011; 112: 858-63.

7. Berkow L, Rotolo S, Mirski E. Continuous noninvasive hemoglobin monitoring during complex spine surgery. Anesth Analg 2011; 113: 1396-402.

8. Vos JJ, Kalmar AF, Struys MM, Porte RJ, Wietasch JK, Scheeren TW, et al. Accuracy of non-invasive measurement of haemoglobin concentration by pulse co-oximetry during steady-state and dynamic conditions in liver surgery. Br J Anaesth 2012; 109: 522-8.

9. Albertin A, La Colla L, Gandolfi A, Colnaghi E, Mandelli D, Gioia G, et al. Greater peripheral blood flow but less bleeding with propofol versus sevoflurane during spine surgery: a possible physiologic model? Spine (Phila Pa 1976) 2008; 33: 2017-22.

10. Lam AM, Gelb AW. Cardiovascular effects of isoflurane-induced hypotension for cerebral aneurysm surgery. Anesth Analg 1983; 62: 742-8.

11. Nakul-Aquaronne D, Sudaka-Sammarcelli I, Ferrero-Vacher C, Starck B, Bayle J. Evaluation of the Sysmex Xe-2100 ${ }^{\circledR}$ hematology analyzer in hospital use. J Clin Lab Anal 2003; 17: 113-23.

12. Lamhaut L, Apriotesei R, Combes X, Lejay M, Carli P, Vivien B. Comparison of the accuracy of noninvasive hemoglobin monitoring by spectrophotometry $(\mathrm{SpHb})$ and HemoCue ${ }^{\circledR}$ with automated laboratory hemoglobin measurement. Anesthesiology 2011; 115: 548-54.

13. Macknet MR, Allard M, Applegate RL 2nd, Rook J. The accuracy of noninvasive and continuous total hemoglobin measurement by pulse co-oximetry in human subjects undergoing hemodilution. Anesth Analg 2010; 111: 1424-6.

14. Gayat E, Bodin A, Sportiello C, Boisson M, Dreyfus JF, Mathieu E, et al. Performance evaluation of a noninvasive hemoglobin monitoring device. Ann Emerg Med 2011; 57: 330-3.

15. Hales JR, Stephens FR, Fawcett AA, Daniel K, Sheahan J, Westerman RA, et al. Observations on a new non-invasive monitor of skin blood flow. Clin Exp Pharmacol Physiol 1989; 16: 403-15.

16. Miller RD, Ward TA, McCulloch CE, Cohen NH. Does a digital regional nerve block improve the accuracy of noninvasive hemoglobin monitoring? J Anesth 2012; 26: 845-50.

17. Chung JH, Ji JY, Kim NS, Seo HY, Gong HY, Kim JW, et al. Efficacy of noninvasive pulse co-oximetry as compared to invasive laboratorybased hemoglobin measurement during spinal anesthesia. Anesth Pain Med 2014; 9: 277-81.

18. Malan TP Jr, DiNardo JA, Isner RJ, Frink EJ Jr, Goldberg M, Fenster PE, et al. Cardiovascular effects of sevoflurane compared with those of isoflurane in volunteers. Anesthesiology 1995; 83: 918-28.

19. Claeys MA, Gepts E, Camu F. Haemodynamic changes during anesthesia induced and maintained with propofol. Br J Anaesth 1988; 60: 3-9. 